\title{
Qualitative Indicators of Social Resilience in Small-Scale Fishing Communities: An Emphasis on Perceptions and Practice
}

\author{
Teresa R. Johnson ${ }^{1}$ \\ School of Marine Sciences \\ University of Maine, United States \\ Anna M. Henry \\ Northeast Fisheries Science Center \\ Maine, United States \\ Cameron Thompson \\ University of Maine, United States
}

\section{Abstract}

This paper reports on ethnographic research aimed at understanding what resilience means to those living within fishery-dependent communities. We draw on semi-structured and oral history interviews, focus groups, and household and business interviews in four Maine fishing communities to examine the reflections of fishermen and other community members on the past, present, and future of their communities, including the threats they face and how they are able to respond to them. Based on our analysis, we identify broad qualitative indicators of resilience: survival, social identity, diversification, getting by, and optimism. The indicators of resilience that we identify are difficult to fully understand using secondary data and, therefore, we argue that understanding them also requires an ethnographic research approach that focuses on the practices of fishermen and the context in which those fishermen live.

Keywords: adaptation, adaptive capacity, fishing communities, qualitative indicators, quantitative indicators, resilience, vulnerability

1 Corresponding author: teresa.johnson@maine.edu. 


\section{Introduction}

Research methods and theories of vulnerability span over 30 years and multiple disciplines (Adger, 2006; Smit \& Wandel, 2006). However, a robust theory of vulnerability has yet to be developed in the social sciences (Davidson, 2010; Kasperson et al., 2001), and global vulnerability assessments remain a research frontier (Schröter et al., 2005). Vulnerability refers generally to the "differential susceptibility to loss from a given insult" (Kasperson et al. 2001, p. 24) and arises from diverse sources, including social relations, technology, biophysical conditions, economic relations, and demography, and therefore we should expect systematic patterns related to vulnerability (Dow, 1992). There is wide agreement that vulnerability has three components: exposure, sensitivity, and adaptive capacity (Adger, 2000; Gallopin, 2006). Exposure refers to the degree, duration, or extent to which a system is in contact with a threat, perturbation, hazard, or stress. Sensitivity is the degree to which the system will be affected if exposed. Adaptive capacity, or resilience, is the ability of the system to endure or recover from exposure to a threat and can also include responses in anticipation of a threat. We focus here on the last component-adaptive capacity or resilience - and follow Adger (2000, p. 347), who, cautioning against transferring the concept of ecological resilience directly to social systems, offers the following definition of social resilience: "the ability of groups or communities to cope with external stresses and disturbances as a result of social, political, and environmental change." Maclean et al. (2013) recently identified six attributes of social resilience through an analysis of six case studies research. Although understanding of the topic is increasing (Berkes \& Ross, 2012), questions remain regarding the social aspects of resilience (Davidson, 2010; Maclean et al., 2013).

Turner et al. (2003) argue that comprehensive vulnerability assessments are unrealistic, and that the differential or variable nature of vulnerability to location calls for place-based research. Similarly, Smit and Wandel (2006) recommend community-based vulnerability assessments that do not specify a priori determinants of resilience. We sought to incorporate these insights into our approach by identifying components or indicators of resilience within communities themselves. Our approach was to explore community members' assessments of their vulnerability and resilience as reflected in their perceptions of the threats they face and how they respond to them. This follows a "people ecology" approach (McCay, 1978) that directs research towards understanding the threats faced by people and how they respond to them, recognizing that responsive units may be individuals, organizations, communities, regions, and other entities. We also recognize that social resilience does not need to be viewed as opposed to or a component of vulnerability, but can be thought of as building strengths and protective factors that help individuals and communities (Maclean et al., 2013). 
Several recent studies have examined vulnerability and resilience in fishing communities (Clay \& Olson, 2008), often in response to legal mandates requiring fishery managers to consider vulnerability and resilience as part of social impact assessments and, to the extent practicable, minimize the potential impacts of fishery regulations on fishing-dependent communities (Clay, 2007; Jacob et al., 2001; Jacob et al., 2010). For example, Jepson \& Jacob (2007), working in the gulf coast of the United States, identified social indicators using secondary data to measure vulnerability of fishing communities. More recently, Jacob et al. (2010) developed quantitative indicators using secondary data to measure vulnerability of gulf coast fishing communities, and social scientists have expanded this work to the northeast United States (Colburn \& Jepson, 2012). These quantitative indicator approaches are a valuable starting point for social impact analysis as they provide low-cost and rapid assessment capability; however, ground-truthing data through qualitative research is still important (Jacob et al., 2010).

Qualitative studies of vulnerability and resilience have also identified components or indicators of resilience. In the northeast United States, Tuler et al. (2008) examined resilience using a useful set of qualitative "driving forces of vulnerability" based on the literature that included demographic, individual decision-making, institutional, economic, sociocultural, technological, and environmental conditions. Marshall \& Marshall (2007), in assessing social resilience to institutional or policy change in northern Australian fishing communities, used quantitative survey data to identify four qualitative components of resilience: (1) perception of risk in approaching change, (2) ability to plan, learn, and organize, (3) perception of the ability to cope with change, and (4) level of interest in adapting to change.

There have been many approaches to studying vulnerability, and these various methodologies reflect that more work is needed in figuring out how best to assess vulnerability. Our study began with fishermen's perceptions of their resilience as a starting point for understanding resilience. ${ }^{2}$ We sought to understand what it means to those living within small-scale fishing communities to be resilient. We believe the indicators of resilience that we identify are difficult to fully capture in secondary data and, therefore, we argue that understanding them requires ethnographic research that focuses on the practices of fishermen and the context in which those fishermen live.

2 Following the convention and preference of those in our study area, we use the term fishermen to include male and female members of the fishing industry. 


\section{Methods}

Our findings are based on ethnographic research conducted from September 2010 to June 2012 in four Maine, United States, fishing communities: Eastport, Lubec, Rockland, and Port Clyde (Figure 1). We draw from 18 semi-structured (Bernard, 2005) and 26 oral history interviews (Colburn \& Clay, 2012; Ritchie, 2003), as well as three focus groups with fishermen and other community members, 37 household surveys, 29 interviews with local businesses, and numerous site visits and informal interviews. Many of those interviewed have transitioned to fishing part-time, or seasonally, with non-fishing related jobs filling the void, yet their identity is firmly rooted in fishing. Although all data from these communities inform our analysis, we draw primarily from the oral history and semi-structured interviews and focus groups. We conducted interviews with current and former fishermen and other community members in order to assess the major threats and changes affecting fishing communities over time, and individual and collective responses to those changes. Maine Sea Grant Marine Extension staff and other community leaders assisted in the initial selection of key informants, which was followed by snowball sampling (Bernard, 2005) to identify additional informants and ensure representation of the diverse fisheries in our study area. Interviews ranged from 1 to 2 hours in length, and were audio-recorded for preservation, sharing (with permission), and analysis. All oral history interviews and six of the semi-structured interviews were transcribed verbatim. For the remaining semi-structured interviews, we took detailed notes from the audio files following the interview guide.

We used QSR International's NVivo 9 qualitative data analysis software to analyze all data collected in this project. Following a modified grounded theory approach (Glaser \& Strauss, 1967; Strauss \& Corbin, 1990), data analysis occurred through the coding and re-coding of the data, followed by additional research necessary to better understand the themes that emerged in the analysis. To ensure consistency in coding across the research team, intercoder reliability assessment was conducted using the NVivo software (Thompson et al., 2004). This served in part to reduce bias associated with single interpretations of data. Following the analysis, we selected quotations from the interviews to illustrate the themes. Focus groups and follow-up discussions served to ground-truth our findings. In this paper, we focus on the themes that emerged in the analysis related to perceptions of resilience as expressed through reflections of fishermen and other community members on the past, present, and future conditions in their communities. 


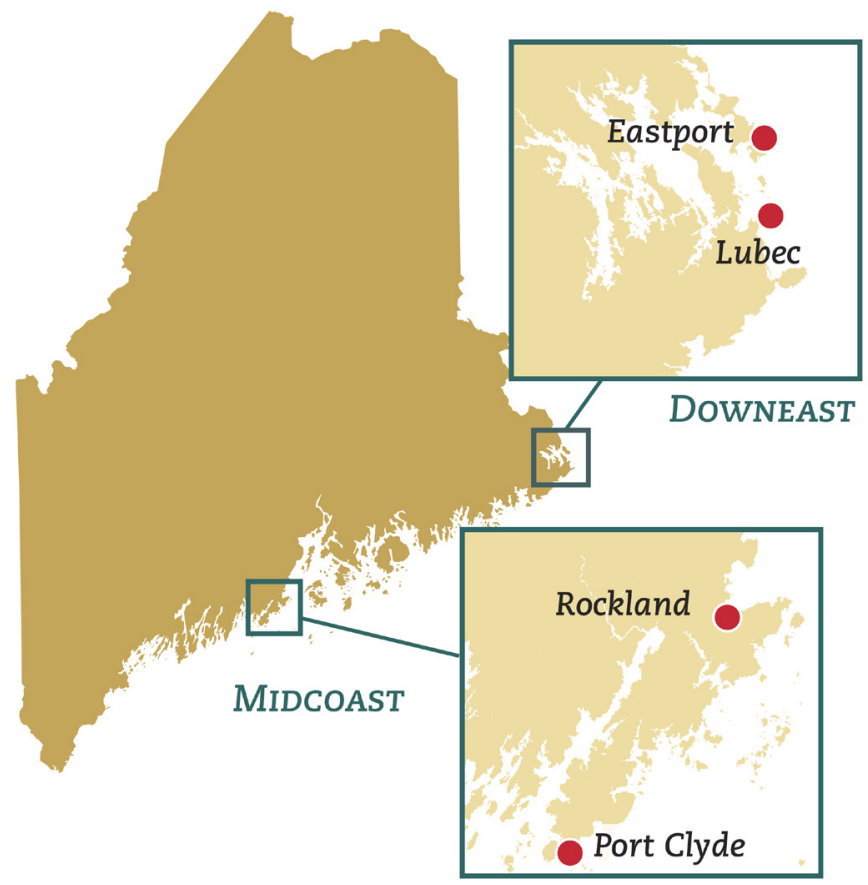

Figure 1. Location of fishing communities in the study area

Source: Kathlyn Tenga-Gonzalez.

\section{Study area and context}

This research took place in four Maine fishing communities. Eastport and Lubec are found in the eastern edge of the state adjacent to Canada within Cobscook Bay, while Rockland and Port Clyde are in the mid-coast region, within and near Penobscot Bay (Figure 1). Eastport and Lubec are isolated and rural with high poverty rates; Port Clyde is relatively isolated and rural with low poverty; and Rockland is more urbanized with high rates of poverty. All four communities have experienced significant social and ecological change in past decades (Table 1). Port Clyde has long experienced an in-migration of wealthy, retired individuals; this has led to higher incomes and property values compared to the other communities. Rockland is the service center for the region, but has experienced significant restructuring with a shift away from natural resource and manufacturing industries to tourism and amenities. The older, wealthier individuals driving these changes tend to live outside of the city, while the population residing in Rockland is supported by lower paying service sector jobs. Corresponding with the loss of opportunities in fishing and other traditional industries, Eastport and Lubec have seen substantial out-migration 
of young individuals. Recently there has been an in-migration of relatively wealthy individuals to these communities, and while incomes and house values are rising they lag far behind that of Port Clyde. Eastport, however, is experiencing an economic resurgence through interest in tourism and the arts, but not necessarily in the fishing sector.

Table 1. Population, age, income, unemployment, poverty and housing statistics for the study communities and the state of Maine

\begin{tabular}{lccccc}
\hline & Lubec & Eastport & Rockland & Port Clyde & Maine \\
\hline Population in 2010 & 1,359 & 1,331 & 7,297 & 2,591 & $1,328,000$ \\
$\begin{array}{l}\text { Population change } \\
\text { since 1960 (\%) }\end{array}$ & -37 & -48 & -17 & +63 & +37 \\
$\begin{array}{l}\text { Population change } \\
\text { since 2000 (\%) }\end{array}$ & -17.7 & -18.8 & -4.1 & +0.43 & +4.2 \\
$\begin{array}{l}\text { Median age } \\
\text { Median income }\end{array}$ & 54 & 54.5 & 43.5 & 51.7 & 42.7 \\
$\begin{array}{l}\text { Individuals unemployed } \\
\text { (\%) }\end{array}$ & 8.8 & 7.2 & 5.7 & 8.6 & 6.5 \\
$\begin{array}{l}\text { Families in poverty (\%) } \\
\text { Houses less than }\end{array}$ & 11.1 & 12.4 & 12.3 & 9.4 & 8.4 \\
\$100,000 (\%) & 49.2 & 49.8 & 19.5 & 7.9 & 21.7 \\
\hline
\end{tabular}

Source: US Census.

Most notably, fishermen in these communities were once diversified; access to groundfish, lobsters, herring, clams, shrimp, scallops, urchins, and other species allowed individuals to respond to annual and seasonal shifts in markets and resource abundance (Brewer, 2011; Hall-Arber et al., 2001). Today, Maine's commercial fishing industry is now highly dependent on a single species: over 80 percent of the value of Maine's fish and seafood landings is from lobster (Steneck et al., 2011). These communities are significantly vulnerable should the lobster resource decline or policies be implemented that otherwise significantly limit the harvest in this fishery (Steneck et al., 2011). Regulations limiting access to key fisheries and stock depletion have reduced opportunities in many of the fisheries and the fishermen left in these communities are aging (Hall-Arber et al., 2001).

\section{Results}

To understand social resilience in these communities, we report themes from our analysis on the perceptions of resilience as expressed in interviews. For the most part, we do not distinguish between the four study communities, as the themes that emerged in the analysis were similar across communities despite 
different social, economic, historical, and environmental conditions. In a few cases, differences did exist and we note them in our presentation of the results. Some of the themes are overlapping and/or related to each other and we note this in our discussion. We use quotes from interviewees to illustrate the themes that emerged in the analysis.

\section{Survival}

The most frequent expression of what resilience means is simply "still fishing" despite having faced numerous threats over the years; that is, they have survived. As an example, one fisherman explained that they have "withstood quite a bit of it now with fishing regulations and some of the idiosyncrasies of it." Similarly, another fisherman explained they are resilient, "Because we've had ... stuff come down on us, and we're still here." The "here" part is important for most whom we interviewed; it's not just that they have survived so that they can go fishing, as some fishermen continue to fish in other parts of the region, but the issue for many is holding on to the tradition of fishing in the community to which they are attached. As indicated in the following quote, not everyone survives:

Well, they have had a lot of changes over the years, the price of fuel going up astronomically, the price of bait going up astronomically, but not the price of their catch going up astronomically, and they're still in business. Some have been weeded out, but others have survived.

The community member below similarly identifies survival as an indicator of resilience, as well as optimism in the future as a secondary indicator. The quote also captures the tenuousness of their survival; they have survived, but that does not mean they will continue to do so.

I think the fact that [fishing is] still here is an indication of that. I can't speak specifically for some of the challenges they may be facing right now, but the fact that you are seeing some investments in lobstering, onshore lobstering facilities whether that's processing or just storage, I don't know, but that to me would indicate optimism about the future.

\section{Diversification}

The next theme is diversification; fishermen often referred to being diversified as enabling resilience, or they talk about diversifying as a strategy to be resilient. This theme has two related dimensions: diversification within and outside of fishing.

As noted, fishermen in Maine have long pursued diverse fishing strategies, and this is particularly true in eastern Maine. One Lubec fisherman described how 
he holds multiple licenses, and harvests less-profitable shellfish when other fisheries are shut down. As he explains it, "When stocks have gone down, I mean being from Washington County, I have to do what [I] can to survive." The quote suggests that this is something natural to fishermen "from Washington County" possibly due to the few economic opportunities in the area. In this way, it suggests that resilience in the form of diversification is part of their social identity, a theme described later.

The quote below further suggests that creativity is an underlying trait among fishermen that enables diversification.

We're fairly creative ... We'll find something else to fish for ... periwinkles - they've been big in the last seven or eight years; now the seaweed industry. We've never really had-well, for so many years we really had no industry, so we've had to get creative to make a living if you want to stay here [in Lubec]. And yeah, so [we're] very resilient, very creative.

This link between creativity and diversification appeared to be widespread among the fishermen we interviewed. As one fisherman explained, resilience is because fishermen "want to make a decent living and so they put their thinking caps on," to "figure [out] a way to survive ... what I call evolving."

The following quote expresses the willingness to "do whatever it takes," which may be within or outside of fishing.

Now I've never went behind [in my payments]. I've never been behind on anything in my life. I always seem to think that there's plenty of stuff to do and there's plenty of money to be made if you just want to get out there and do it. You've just kind of got to set your ego aside and get in there and do whatever it takes. Today, my thing is I do everything that nobody else wants to do.

The fisherman below explains how it came to be that fishermen are "still here." A driver for this is having investments in the fishery (e.g., boat payments) that require them to "try new things" or "diversify" in order to survive. In this case, the fisherman is planning to put a new kind of twine in his net to help address bycatch and rising fuel costs, another example of fishermen's creativity and innovation.

You gotta make the payments, so you just try different things. Keep trying new things. Like this twine that I'm putting in my net. That's going to help ... Just diversify, like I did. What other choice do we have? 
Similarly, the fisherman below describes diversification as a resilience strategy, but uses the language of adaptation instead. Again, we see innovation in fishing technology as important to resilience:

Yes, I think they've had to adapt to both the changes in the stocks, with declines, and adapt to new types of fisheries and grab the new type of gear to catch - they develop their own types of scallop drags. I think they have been very resilient.

Fishermen most often talk about needing to survive new regulations; the implication is that if they can't respond appropriately, they will go out of business:

I've had to adapt and change my way of how I fish as a business ... It's a survival thing ... I've adapted all these regulations, all these years. I've tried to make regulations work in my favor where I can stay in business.

This fisherman is talking about following new regulations, but while doing so adapting his behavior in ways to minimize the impact of the change on his business. Changes made in response to new regulations could fall under more substantive changes or "adaptations," or they might involve coping. For example, a coping response to catch limit per trip might be to fish closer to shore to make more frequent, but shorter trips with the end result being that they catch the same amount of fish over the season. An example of a more substantive adaptation might be investing in new technology or a larger boat to pursue a new fishery. Some fishermen, however, report having little choice but to live with new regulations, suggesting they may be less resilient. Fishermen often state that they hope effort controls are temporary, while acknowledging that regulations rarely are relaxed.

The fisherman below also indicates that diversification is key to resilience, but that it is becoming more and more difficult due to regulations, perhaps suggesting fishermen are reaching a threshold in their ability to adapt. He indicates that this has led to them having to "fight," suggesting it is different than what they have done before to survive.

We're survivors. We continue to maintain ... yes. But that resilience is becoming harder to obtain and harder to achieve with all of the new laws and regulations that come down because some of the avenues that we've gone into to be resilient are being taken away from us every day. We have a new problem now. We're fighting. We're fightin' for our lives to be able to continue.

The threshold that is implied above refers to a reduction in their ability to be diversified. As indicated below, this is a significant concern for fishermen dependent on the lobster fishery. 
So your lobster stocks collapse [hypothetically] ... from a shell disease [then] this town's [in big trouble] because we're not diverse enough to handle something like that and probably in the '90s when it was diverse, it was scallopers, draggers, lobstermen, all of the above, and everybody made a living doing a little bit of everything, but now it's basically all their eggs are in lobstering except for a scattering few.

This is less of an issue in Eastport and Lubec because fishermen there are generally more diverse and few rely solely on lobster compared to the midcoast region.

Another perspective of resilience relating to "diversification" is having a "back up plan" to get by during difficult times. This may mean diversifying in response to a problem, but it also includes being ready to diversify in anticipation of problems. Again, the temporal dimension becomes important. Diversification can still involve fishermen's skills and expertise as captains and fishermen, such as diving for aquaculture companies, running whale watching tours, and working for the shipping industry.

Also important are jobs that fishermen turn to outside of the fishing sector, such as driving trucks or construction work. One fisherman estimated that during the summer at least 50 percent of the commercial fishermen in Eastport work part-time outside of fishing. When asked if fishermen in his community were resilient, one fisherman from Eastport explained that fishermen resist change, but most have other jobs to fall back on.

I mean nobody wants it. If we have to, we will ... All the fishermen that fish always have something else to fall back on. I mean some of the guys cut wood, some of them have other jobs.

At a higher scale, non-fishing community members are also creating alternative economic opportunities. This diversification in the communities is reflected in how those outside of the fishing industry often talk about resilience in the community. In Rockland, for example, we heard resilience described as new economic opportunities that come with tourism-one community member explained, "Without a doubt the community is resilient, you see what it's evolved from and to in the last 20 years, and its dramatic differences. Main Street is thriving." Indeed, in Rockland this transition is most visible in its efforts to promote the arts and tourism. In Lubec, a town official explained, "We are probably one of the most resilient former fishing communities because of our talented workforce and tourism. The strengths are in the diversity of our community" (emphasis added). In both Lubec and Eastport, tourism is being promoted and there are positive signs of economic development, although less so than in Rockland. Eastport and Lubec are also promoting new industries, such 
as tidal and wind power. The implications of economic diversification outside of fishing, and the gentrification that they may stimulate, is uncertain: Will these changes help or hinder the fishermen in the community? Will changes further threaten fishermen's access to the waterfront? Does the resilience of the community come at the expense of fishermen? These are important questions to understanding resilience in these communities. For some, these changes are welcome; for others, there is great concern that fishermen will be marginalized even further in the community. This is reflected in their belief in their ability to survive and optimism about the future.

\section{Getting by}

In contrast to adapting for "survival," such as through a diversified fishing portfolio, resilience is also expressed when fishermen describe responding to threats or change as simply "getting by," or making small changes to get through difficult times. When they talk about getting by, fishermen often refer to "tightening up your belt" or "knuckling down" during hard times. According to one respondent, fishermen "have been inconvenienced many times and lived through hardship many times." Another fisherman explained, "When times get tough, [fishermen] just knuckle down ... and watch their expenses. You always hope for a good year."

The need for this kind of resilience is driven by volatile fuel costs and prices in the fishery, as well as more global economic downturns and recessions. Also part of "getting by," some fishermen are flexible and able to respond quickly to change. This has been described as being practical; one fisherman explained: "I mean almost on a daily basis you're adapting to one thing or another."

Some strategies are temporary responses to short-term conditions, and once the crisis is over, they return to their normal activities. But strategies for "getting by" could lead to long-term innovations and creativity, such as new fishing strategies and technologies (such as the new twine described earlier).

Another example of "getting by" is increasing reliance on income and support from family members, particularly spouses. Fishermen we interviewed acknowledged the vital contributions from their spouses that helped them "get by." Examples of important and direct contributions to the fishing business include bookkeeping, submitting necessary paperwork such as permit applications and landings data, maintaining fishing gear, and representing fishermen at fishery management meetings. In addition, spouses also provide key support through non-fishing employment that offers supplemental income and, often more importantly, health benefits. 


\section{Social identity}

Several fishermen indicated fishing is part of their social identity and this keeps them resilient, preventing them from giving up during hard times. As an example, one fisherman explained, "Because the ones that fish, that's what they want to do. It's in their blood and they do it. Doesn't matter if it's a bad year or a good year, no, they're gonna do it."

Most importantly, their history and dependence on fishing drives their resilience, defined broadly as "finding a way to keep fishing going in the community" or being "a tradition" that persists. This is described by one fisherman:

Tradition, just the fishing tradition, people are entrenched in the fishery, resilient. People of this community - there's a lot of heritage so people are always gonna want to go fishing - find a way to go fishing.

Some fishermen spoke about how the broader community helps fishermen, providing them with some resilience to "bounce back" after difficult times. For example, one community member explained when asked if the community was resilient:

Yeah, I suppose. I mean. They always bounce back ... I know one time, they have a supper to raise money for somebody ... It's a small community, they all kind of stick together.

In many of our interviews with fishermen, we heard echoes of Princen's (2005) "logic of sufficiency" expressed. For example, when asked how fishermen in the community were doing, one fisherman responded, "I wouldn't say very well, but we're getting by."

Indeed, "getting by" here refers to the quality of life; they are not doing great, but not too bad either, and that is OK. It is clear that this "getting by" attitude is part of their social identity. As one fisherman explained, "We have seen bad times before, will see them again. If you don't expect as much because of upbringing and work you've had, then you don't need as much." In other words, they are happy doing "not great" because they are satisfied that their needs are met with what they have.

Similarly, in addition to having jobs to fall back on, some fishermen indicate resilience also comes from "saving for a rainy day." In other words, "it goes in cycles," so they do not spend beyond their means in anticipation of bad years. Not all fishermen do this well, however, and this is viewed as contributing to some of the financial problems in the industry.

I think it's resilient. I think most of the financial problems - a lot of them fall back on individuals, on how they live ... You know, we lived 
close to what we made ... Whereas, now, they've got to have bigger, faster boats. They've got to have snowmobiles, and I think the business end of it maybe - has [been] forgotten a little bit ... I think that's like a lot of the young people growing up with different visions of how you get by.

The same fisherman told a story of an old captain who told him that he "wouldn't get rich fishing," but that he "wouldn't starve to death" either; the point he was making to us is that for him (and his fellow fishermen), getting by is enough.

This theme also suggests that resilience transcends the actions and decisions of individual fishermen, and the role of the larger community should not be ignored. In some cases, like Port Clyde, Eastport, and Lubec, the "broader community" includes non-governmental organizations (NGOs) that provide organizational and financial support for fishermen to respond to change. In Port Clyde, an NGO was instrumental in providing adaptive capacity for fishermen, helping them develop a new marketing brand, a community-supported fishery, a groundfish sector, and a permit bank (the latter two enables their participation in the region's catch share program). We also see this in the Cobscook Bay communities where a local NGO has provided fishermen with organizational support and has facilitated dialogue in the community that has enabled fishermen to respond to past threats. The NGO is also working with fishermen to improve marketing of their fish products.

\section{Optimism}

As indicated earlier, optimism appears to be another indicator of resilience, seen as investment in the future. On the other hand, lack of optimism (little or no investment in the future) suggests a loss of resilience, and generally a lack of overall well-being. This is expressed when we asked people to reflect on the future of their communities. The lack of optimism was most pronounced in stories of drugs and alcoholism. Many fishermen lamented these difficult times, as expressed in the following quote.

I saw whole families break up. I saw people lose everything they had. I saw people get divorced. Some people killed themselves. People turned into drug addicts, they turned to drugs because they couldn't pay for boats, wharfage, insurance, truck payments, house payments, college loans.

One fisherman also made a connection between lack of optimism and resilience. When asked if the fishing community was resilient, he explained, "probably not as resilient as they could be without different socioeconomic difficulties." And when asked what socioeconomic difficulties were preventing resilience for these fishermen, he explained further: 
Probably drug abuse and alcoholism and those kinds of things ... Well, I think it's a problem everywhere really when you ... dip into the lower income levels ... you tend to lose your hope and your faith in the process and in the future and stuff. You dip into that ... A lot of it is just plain lack of hope really.

\section{Discussion}

Recent studies examining vulnerability and resilience in fishing communities have focused on quantitative indicators of secondary data (Colburn \& Jepson, 2012; Jepson \& Jacob, 2007) or analyses of survey data (Marshall \& Marshall, 2007; Pollnac \& Poggie, 2008), and significant effort has been done to develop a robust set of indicators for measuring well-being of fishermen (Pollnac \& Poggie, 1988, 2008; Smith \& Clay, 2010). These approaches offer potentially low-cost and rapid social impact assessment capability. Our research took a qualitative approach to understanding what it means to those living within fishery-dependent communities to be resilient through reflections of fishermen and others on the past, present, and future of their communities, including the threats they face and how they are able to respond to them. Based on our analysis, we identify five broad "qualitative indicators" of resilience: survival, social identity, diversification, getting by, and optimism.

The fishermen in our study, as elsewhere, continue to face dynamic social and environmental threats that they must be willing and able to respond to if they are to survive. In our interviews, a key indicator of resilience is simply that fishermen are "still fishing" or "being survivors," and that fishing remains part of the community. This qualitative indicator could be quantified, for example, by asking a simple question: Is there fishing going on in the community, yes or no? However, whether there are enough fishermen "still fishing" or they are fishing enough would be more difficult to quantify and would likely differ for each community. Some communities with a longer or more established history and culture of fishing might require a higher level of fishing activities to occur than a community where fishing is only a small part of the overall economy of the area. This latter aspect relates to the next theme, social identity.

Interviews point to fishermen's social identity as fishermen as a key indicator of resilience, and secondarily that this social identity compels them to respond to survive, whether it be coping or adapting. In many cases their identity as fishermen push them to make the necessary changes to adapt to new social and environmental conditions; they want to survive so that they can still be fishermen. Without this identity, fishing is just a job, and people who have viewed it in that way have already rationally decided to leave fishing due to the cumulative difficulties; that is, they have lost their willingness to endure 
the hardships. At a higher scale, our findings also suggest that the community's identity as a fishing community creates resilience. Fishermen receive support for adaptation from the broader community, such as through charity dinners and relief funds. In Port Clyde, the broader community has embraced the fishermen's local marketing initiative; without their willingness to pay more for fresh, local fish, fishermen would not benefit from the program during low-volume harvests. Related to social identity, fishermen also want to see a future for their community that includes fishermen; and many currently do not because there are few opportunities for new fishermen to enter the fishery. This may contribute to the loss of social identity, and subsequent loss of fishermen's resilience. Rather than through secondary data, social identity could be measured in a rapid assessment that would require visits to fishing communities. For example, a researcher might follow a scale for measuring the "level of industry attachment" as described by Marshall and Marshall (2007).

Our research also suggests that once a threshold of impacts or vulnerability is reached, fishermen and the broader community begin to lose hope and optimism about the future. This qualitative indicator, pessimism (or lack of optimism or hope) about the future, reflects individuals' ability to respond to problems, or invest in the future. During difficult times, some fishermen turn to drugs and alcohol (sometimes they recover, but not always). In our research, this appeared more pronounced in remote, isolated areas. We theorize that the cumulative effect of losing optimism can impact the social identity of the community, further impacting its resilience and fishermen's ability to "survive." Optimism might be analogous to job satisfaction and well-being, and therefore could be quantified using established well-being and job satisfaction measures (Gatewood \& McCay, 1990; Pollnac \& Poggie, 1988, 2008). Optimism also could be measured through surveys using statements like those identified by Marshall \& Marshall (2007), such as, "I am more likely to adapt to change compared to other fishers I know," or, "If there are any more changes I will not survive much longer." This too would require visits to the fishing communities, rather than collection of data through censuses or other secondary data sources.

A key strategy includes activities we termed "getting by," which is similar to "coping" (McCay et al., 2011) because it involves very low levels of response. It refers to the short-term efforts made only during hard times - "tightening belts" - such as using less bait, minimizing fuel expenses by driving boats more slowly, or putting off maintenance and repair - or even non-fishing expenses, like eating out less. In this case, fishermen return to normal activities once the crisis is over. These practices and strategies are important components of fishermen's resilience, but would be difficult to measure through secondary data 
collected every 5-10 years or through a structured survey. We could imagine using checklists as part of rapid assessments that could try to capture some of these "getting by" strategies.

Diversification emerged as an important indicator of resilience. McCay (1978) describes diversification as a strategy that allows individuals to "cope with problems." It involves "spreading of the risk" and includes activities within or outside of fishing like diversifying their gear, investing in other fisheries, and occupational pluralism - that is, drawing on non-fishery occupations and government welfare for subsistence (McCay, 1978). Fishermen can adopt diversified strategies in anticipation of threats and the need to respond. These may stem from, for example, social memory or expectations that fish stocks are cyclical or inherited local ecological knowledge of stock fluctuations about good years and bad years. In this way, fishermen's resilience is from being proactive and expecting change, and is tied to their identity of being creative. Alternatively, some fishermen may only diversify when something goes wrong - an unexpected stock collapse, loss of a market due to global forces, or emergency fishery regulations, for example. These may call for short-term or long-term diversification. In this case, diversification is reactive, in response to change. Diversification could be measured through types of permits used (and/or available) or landings, but interviews and participant observation with fishermen would be ideal ways to gather data on fishing practices and the extent that fishermen diversify, including under what conditions they diversify and how they do this, as well as the consequences of their diversification.

Finally, our research highlights the importance of broader institutional forces intervening to enable and even promote diversification efforts as critical. For some communities, institutional support from the private or public sector is needed to maintain or enhance resilience when facing particular threats. While we can readily document the presence or absence of such NGOs and communitysupport institutions, additional field research would be needed to understand how these groups interact with local fishermen and the ways in which they aid or hinder their resilience.

In conclusion, we recognize that many of the qualitative indicators that we have identified could be quantified or measured in some way and overlap with those already identified in the literature. Survival could be quantified simply as the presence or absence of fishing (e.g., through fish landings or numbers of active fishing vessels). Diversification could be quantified by simply counting numbers of licenses available and utilized. And optimism could be measured through existing well-being indicators. However, we argue that it is also critical to understand the practices that fishermen pursue to "survive" or simply "get by." We believe it is insufficient to know the information provided by secondary data such as how many licenses a fisherman owns and whether they 
use them or not. We also want to know which licenses they have, which licenses they would like to have, and when and how they use them in relation to each other. Understanding individual practices would be difficult, if not impossible, to capture with secondary data alone. Furthermore, only through qualitative studies can we capture how a fishermen's individual perspective on their identity influences resilience. Thus, we propose that along with the important work being done to develop quantitative social indicators of vulnerability and resilience using secondary data, ethnographic research and fieldwork in fishing communities is also needed to pursue and document qualitative indicators that capture the complexities of fishermen's behaviors, their practices, responses, and perceptions of change.

\section{Acknowledgments}

This research was supported by grants from Maine Sea Grant, the Maine Agriculture and Forest Experiment Station, and Maine's Sustainability Solutions Initiative. The authors would like to thank all of those who were interviewed and otherwise contributed to this research. Chris Bartlett of the Maine Sea Grant and the University of Maine Cooperative Extension provided valuable support and assistance with interviews, focus groups, and other outreach efforts. The Cobscook Bay Resource Center and the Cobscook Bay Fishermen's Association helped identify participants in Eastport and Lubec.

\section{References}

Adger, W. N. (2000). Social and ecological resilience: Are they related? Progress in Human Geography, 24(3), 347-364. doi: 10.1191/030913200701540465

Adger, W. N. (2006). Vulnerability. Global Environmental Change, 16(3), 268-281. Berkes, F., \& Ross, H. (2012). Community resilience:Toward anintegrated approach. Society \& Natural Resources, 26(1), 5-20. doi: 10.1080/08941920.2012.736605

Bernard, H. R. (2005). Research methods in anthropology: Qualitative and quantitative approaches (4th ed.). Walnut Creek: Altamira Press.

Brewer, J. (2011). Paper fish and policy conflict: Catch shares and ecosystembased management in Maine's groundfishery. Ecology and Society, 16(1). Retrieved from http:/www.ecologyandsociety.org/vol16/iss11/art15/

Clay, P. M. (2007). Defining fishing communities: Issues in theory and practice. NAPA Bulletin, 28(1), 27-42. doi: 10.1525/napa.2007.28.1.27

Clay, P. M., \& Olson, J. (2008). Defining "fishing communities": Vulnerability and the Magnuson-Stevens Fishery Conservation and Management Act. Human Ecology Review, 15(2), 143-160. 
Colburn, L. L., \& Clay, P. M. (2012). The role of oral histories in the conduct of fisheries: Social impact assessments in northeast US. Journal of Ecological Anthropology, 15(1), 74-80.

Colburn, L. L., \& Jepson, M. (2012). Social indicators of gentrification pressure in fishing communities: A context for social impact assessment. Coastal Management, 40(3), 289-300. doi: 10.1080/08920753.2012.677635

Davidson, D. J. (2010). The applicability of the concept of resilience to social systems: Some sources of optimism and nagging doubts. Society \& Natural Resources, 23(12), 1135-1149. doi: 10.1080/08941921003652940

Dow, K. (1992). Exploring differences in our common future(s): The meaning of vulnerability to global environmental change. Geoforum, 23(3), 417-436.

Gallopin, G. C. (2006). Linkages between vulnerability, resilience, and adaptive capacity. Global Environmental Change, 16(3), 293-303.

Gatewood, J. B., \& McCay, B. J. (1990). Comparison of job satisfaction in six new jersey fisheries: Implications for management. Human Organization, 49(1), $14-25$.

Glaser, B. G., \& Strauss, A. L. (1967). The discovery of grounded theory: Strategies for qualitative research. New York: Aldine Publishing Company.

Hall-Arber, M., Dyer, C., Poggie, J., McNally, J., \& Gagne, R. (2001). New England's fishing communities. MITSG 01-15, MIT Sea Grant College Program, 292 Maine Street, E38-300, Cambridge, MA 02139.

Jacob, S., Farmer, F. L., Jepson, M., \& Adams, C. (2001). Landing a definition of fishing dependent communities: Potential social science contributions to meeting National Standard 8. Fisheries, 26(10), 16-22. doi: 10.1577/1548-8446(2001)026<0016:ladofd >2.0.co;2

Jacob, S., Weeks, P., Blount, B. G., \& Jepson, M. (2010). Exploring fishing dependence in gulf coast communities. Marine Policy, 34, 1307-1314.

Jepson, M., \& Jacob, S. (2007). Social indicators and measurements of vulnerability for gulf coast fishing communities. Napa Bulletin, 28(1), 57-68.

Kasperson, R. E., Kasperson, J. X., \& Dow, K. (2001). Introduction: Global environmental risk and society. In J. X. Kasperson \& R. E. Kasperson (Eds.), Global environmental risk (pp. 1-48). London: Earthscan Publications.

Maclean, K., Cuthill, M., \& Ross, H. (2013). Six attributes of social resilience. Journal of Environmental Planning and Management, 57(1), 1-13. doi: 10.1080/09640568.2013.763774

Marshall, N. A., \& Marshall, P. A. (2007). Conceptualizing and operationalizing social resilience within commercial fisheries in northern Australia. Ecology and Society, 12(1), 1. Retrieved from http://www.ecologyandsociety.org/ vol12/iss11/artl1/ 
McCay, B. J. (1978). Systems ecology, people ecology, and the anthropology of fishing communities. Human Ecology, 6(4), 397-422.

McCay, B. J., Brandt, S., \& Creed, C. F. (2011). Human dimensions of climate change and fisheries in a coupled system: The Atlantic surfclam case. ICES Journal of Marine Science, 68(6), 1354-1367.

Pollnac, R. B., \& Poggie, J. J. (1988). The structure of job satisfaction among New England fishermen and its application to fisheries management policy. American Anthropologist, 90(4), 888-901. doi: 10.1525/aa.1988.90.4.02a00070

Pollnac, R. B., \& Poggie, J. J. (2008). Happiness, well-being and psychocultural adaptation to the stresses associated with marine fishing. Human Ecology Review, 15(2), 194-200.

Princen, T. (2005). The logic of sufficiency. Cambridge: MIT Press.

Ritchie, D. A. (2003). Doing oral history: A practical guide. USA: Oxford University Press.

Schröter, D., Polsky, C., \& Patt, A. G. (2005). Assessing vulnerabilities to the effects of global change: An eight step approach. Mitigation and Adaptation Strategies for Global Change, 10(4), 573-595.

Smit, B., \& Wandel, J. (2006). Adaptation, adaptive capacity and vulnerability. Global Environmental Change, 16(3), 282-292.

Smith, C., \& Clay, P. (2010). Measuring subjective and objective well-being: Analyses from five marine commercial fisheries. Human Organization, 69(2), $128-158$.

Steneck, R. S., Hughes, T. P., Cinner, J. E., Adger, W. N., Arnold, S. N., Berkes, F., ... Worm, B. (2011). Creation of a gilded trap by the high economic value of the Maine lobster fishery. Conservation Biology, 25(5), 904-912.

Strauss, A., \& Corbin, J. (1990). Basics of qualitative research: Grounded theory, procedures and techniques. Newbury Park, CA: Sage Publications.

Thompson, C., McCaughan, D., Cullum, N., Sheldon, T. A., \& Raynor, P. (2004). Increasing the visibility of coding decisions in team-based qualitative research in nursing. International Journal of Nursing Studies, 41(1), 15-20. doi: http://dx.doi.org/10.1016/j.ijnurstu.2003.03.001

Tuler, S., Agyeman, J., Pinto da Silva, P., Roth LoRusso, K., \& Kay, R. (2008). Assessing vulnerabilities: Integrating information about driving forces that affect risks and resilience in fishing communities. Human Ecology Review, 15(2), 171-184.

Turner, B. L., Kasperson, R. E., Matson, P. A., McCarthy, J. J., Corell, R. W., Christensen, L., ... Schiller, A. (2003). A framework for vulnerability analysis in sustainability science. Proceedings of the National Academy of Sciences, 100(14), 8074-8079. 
This text taken from Human Ecology Review Volume 20, Number 2, 2014, published 2014 by ANU Press, The Australian National University, Canberra, Australia. 